the inner city areas if they are not to perpetuate Sir Keith Joseph's cycle of deprivation.

Professor Court believes that medical services could be improved in such areas with little extra money-and he points to the success of enthusiasts in Sheffield, where the hospital accident and emergency departments have taken some of the responsibility for primary care and health visitors have been trained to identify and help the families at greatest risk. Yet -as ITV's World in Action showed last week-cuts in NHS resources are hitting hard in many of these areas-forcing the closure, for example, of a specialist maternity hospital in Liverpool, with its exceptional poverty and large numbers of women with high risk pregnancies.

The next generation of children is our investment in the future, and it is just as important as the industrial investment that economists tell us we have lacked. Here the GMS response to the Court Report is surely right in calling for selective action. While resources are scarce they need to be concentrated into the neediest areas. At its best the NHS provides primary care and obstetric and paediatric services of as good a quality as anywhere in the world; yet the worst areas of urban deprivation often coincide with a standard of medical care at the opposite end of the spectrum. Attempts by the DHSS to share a small NHS cake (smaller in proportion than our northern European neighbours, while our defence budget is larger) have concentrated on concepts of fairness and on mathematical formulae. Instead, we should be identifying NHS districts with high social and medical morbidity and investing resources there in ways that have been shown to be effective.

\footnotetext{
${ }^{1}$ Committee on Child Health Services (chairman, Professor S D M Court), Fit for the Future. London, HMSO, 1976.
}

2 British Medical fournal, 1976, 2, 1524.

\section{Topical antibiotics}

Topical antibiotic preparations have a variety of uses. Firstly, to treat primary bacterial skin infections; secondly, to eradicate pathogens from carrier sites; and, thirdly, to lessen infection of granulating surfaces such as leg ulcers and burns. Local application of an antibiotic gives rise to two hazards; the patient may develop contact dermatitis, and organisms sensitive at the start of treatment may develop resistance. Both hazards have been encountered with most antibjotics since penicillin was introduced. Skin sensitivity occurs most easily when chronic venous leg ulcers and varicose eczema are treated. Even simple ointment bases containing lanolin and no antibiotic may provoke dermatitis, now a well-recognised complication ${ }^{1}$ of the treatment of "bad legs."

Neomycin appeared to be the ideal local application when it was introduced, and it was some years before staphylococci were shown to have developed resistance. At that time neomycin had not been used systemically to any large extent. Sadly, it proved to be a potent sensitiser: $:^{2} 1760$ cases of neomycin dermatitis were reported from Finland ${ }^{3}$ after 12 years' use, and it will produce cross-sensitisation with kanamycin, framycetin, bacitracin, and gentamicin. ${ }^{4}$ Gentamicin ointment, too, was thought an excellent preparation for treating skin infections and leg ulcers when it was used ${ }^{5}$ on 146 patients in the Belfast City Hospital in 1969. No sensitisation occurred, and only six resistant organisms were found. As had been the case with neomycin, gentamicin had been used very little for systemic infection and its wide spectrum of effect against staphylococci, streptococci, pseudomonas, and proteus made it attractive as a topical antibiotic. At Belfast the use of gentamicin ointment steadily increased, until in 1975-6 some $90^{\circ}$, of the total of 23020 15-gramme units used in the hospital were used in the skin department. ${ }^{6}$ Nevertheless, within a few months there was an epidemic of infection due to gentamicin-resistant organisms.

Between December 1975 and March 1976 gentamicinresistant strains of Staphylococcus aureus were isolated from 23 patients, from three members of the staff, and from physical structures in the hospital. Of 58 isolates, there were eight differing patterns of resistance to 18 antibiotics and seven bacteriophage types. ${ }^{6}$ The epidemic was controlled by halting the admission of new patients to the dermatological beds and severely restricting the use of topical gentamicin. This episode is not unique. Lacey had suggested ${ }^{7}$ in 1975 that it was only a matter of time before resistance to gentamicin in Staphylococcus aureus became widespread in the same way that resistance to neomycin suddenly emerged. In view of another epidemic of gentamicin-resistant staphylococci in three hospitals ${ }^{8}$ and a single isolation of a gentamicinresistant staphylococcus after topical use, ${ }^{9}$ Lacey's prediction is becoming a reality. Gentamicin has become more widely used for treating severe systemic infections by Gram-negative organisms. ${ }^{10}$ In one burns unit its effect was so dramatic in the control of pseudomonas infection that its topical use was forbidden in case resistant strains were produced. ${ }^{11}$ This restriction should, perhaps, be more widely applied if the antibiotic is not to lose much of its value.

Would a move away from the use of topical antibiotics harm patients? Probably not. The mainstay of treatment of stasis or gravitational ulcers is adequate elastic support. Certainly ulcers act as a good growth medium for a mixed flora of pathogens, but there is little evidence that their removal speeds healing. ${ }^{12}$ In 17 patients whose ulcers were colonised by yeasts those in which the yeasts were removed by nystatin healed no more rapidly. ${ }^{13}$ Simple non-sensitising applications such as eusol, saline, or chlorhexidine avoid the problem of generating antibiotic-resistant organisms, and even the ubiquitous pseudomonas can be controlled with $5^{\circ}$ acetic acid solution. ${ }^{14}$

In treating carrier sites the doctor may have to use a topical antibiotic, but bacteriological investigation should precede treatment so as to establish the sensitivity of the organism. The risk of neomycin sensitivity is less in children, and though not all would agree it still has a place in the topical treatment of pyogenic infections of the skin.

${ }^{1}$ Cronin, E, British fournal of Dermatology, 1966, 78, 167.

${ }^{2}$ Kirton, V, and Munro-Ashman, D, Lancet, 1965, 1, 138.

3 Pirilâ, V, Förström, L, and Rouhunkoski, S, Acta Dermato-venereologica, 1967, 47, 419.

4 Pirilä, V, Hirvonen, M-L, and Rouhunkoski, S, Dermatologica, 1968, 136, 321.

5 Jefferson, J, and McNight, A G, British fournal of Clinical Practice, 1969, 23, 133.

'Wyatt, T D, et al, fournal of Antimicrobial Chemotherapy, 1977, 3, 1.

7 Lacey, R W, Bacteriological Reviews, 1975, 39, 1.

${ }^{*}$ Speller, D C E, et al, Lancet, 1976, 1, 464.

${ }^{9}$ Porthouse, A, et al, Lancet, 1976, 1, 20.

10 Noone, P, Pattison, J R, and Davies, D G, Postgraduate Medical Fournal, 1974, 50, suppl 7, 9.

${ }^{11}$ Settle, J A D, Postgraduate Medical fournal, 1974, 50, suppl 7, 54.

${ }^{12}$ Noble, W C, and Somerville, D A, Microbiology of Human Skin, p 261. Philadelphia, Saunders, 1974.

13 Smith, R J, English, M P, and Warin, R P, British fournal of Dermatology, 1974, 91, 697.

${ }^{14}$ Phillips, I, et al, Lancet, 1968, 1, 11. 